\title{
The public Swiss natural hazard portal for warnings and recommended behaviour
}

\author{
Christophe Lienert a,*, Franziska Angly ${ }^{\mathrm{a}}$, Barbora Neveršil ${ }^{\mathrm{b}}$, Daniel Meier ${ }^{\mathrm{c}}$ \\ a Secretariat Steering Committee Intervention in Natural Hazards LAINAT, c/o Swiss Federal Office for the Environment FOEN - \\ christophe.lienert@bafu.admin.ch,franziska.angly@bafu.admin.ch \\ ${ }^{b}$ Swiss Federal Office for the Environment FOEN - barbora.neversil@bafu.admin.ch \\ ${ }^{c}$ Swiss Federal Office for Meteorology and Climatology MeteoSwiss-daniel.meier@meteoswiss.ch \\ * Corresponding author
}

Keywords: natural hazard, warning, public, platform, map, pictograms

\begin{abstract}
:
The public Swiss natural hazard portal (NHP), accessible on https://www.natural-hazards.ch, is a web-based cartographic, real-time information service to the Swiss public. It provides warnings and recommended behaviour before, during and after natural hazard events. The NHP, in its first version, went live in 2014. The most current version, comprising cartographic enhancements and complementary pictographic material, is online since August 2020. The NHP is a milestone achievement in the implementation of the Swiss Federal Council's resolution "Optimization of Warnings and Alerting" (OWARNA), adopted after the game-changing, countrywide floods of 2005 and 2007. Aiming at improving the protection of the civilian population and the related warning processes, the portal was realized jointly by the Steering Committee Intervention in Natural Hazards (LAINAT), a committee established in late 2008, encompassing four Federal offices and two Federal research Institutes. The LAINAT is responsible for consulting, coordinating and developing natural hazard warnings at the strategic and operational level within the Swiss Federal administration (Wernli-Schärer et al. 2016).
\end{abstract}

Its distinct topography and regional climatic variations make Switzerland prone to a number of different hazards, including gravitational, water-related, climate-related and tectonic hazards. Switzerland has undergone tremendous sociodemographic changes in recent decades. Over the past half-century, its total population increased from 4.6 million people to well over 8 million in 2016 (8.7 million in 2020). As a consequence, housing and transport infrastructure grew rapidly, and so did the damage potential. About $22 \%$ of the Swiss population lives in flood-prone areas and about $30 \%$ of Switzerland's jobs - thus a significant part of the country's value creation - are also located in these areas (OECD 2017).

The NHP follows a 'one-stop shop', cartographic concept to deliver and obtain information on eleven hazard categories - in five languages: German, French, Italian, Raetho-Roman, and English. The synoptic overview map on the entry page (Fig. 1) enables users to obtain real-time information about the overall natural hazard situation in Switzerland. Five harmonized warning levels are applied from "no/minor danger" (green), moderate danger (yellow), considerable danger (orange), high danger (red) to very high danger (dark red). The raster-based web-map is overlaid by an interactive map layer, allowing to gain further situational insight on hazards-specific warning regions, river sections or lakes. The plain raster map (without the interactive layer) may also be easily embedded into third party websites, allowing to spread natural hazard warnings widely, e.g. on news portals or on other highly frequented websites.

Only a few clicks enable users to retrieve a real-time situational natural hazard analysis round the clock, detailed spatial information on every zip-code location in the country, a customizable list of current hazard bulletins, and news releases. Further, a cartographic overview and a dashboard-like summary on all eleven hazards, complemented by maps for each single hazard, allow to gain a quick overview on the natural hazard situation in Switzerland. The portal also provides static information in terms of historicized hazard bulletins, as well as general advice on recommended behaviour before, during and after specific hazards. These recommendations are presented as partly animated pictograms, realized by scalable vector graphics. The entire NHP is able to handle a very large number of simultaneous visitor requests, with an agreed availability of $99.5 \%$, and has proven to be highly reliable to date.

\section{References}

OECD, 2017. Boosting Disaster Prevention through Innovative Risk Governance. Insights from Austria, France and Switzerland. OECD Reviews of Risk Management Policies, OECD Publishing, Paris, https://doi.org/10.1787/9789264281370-en. 
Wernli-Schärer L., Bialek R., Buser M., Flury C., Gerber B., Haslinger F., Hegg C., Ottmer B., Overney O., Romang H., Schmutz C., Schweizer J., 2016. Strategies for the reduction of natural hazards damages by optimized warning, alarming and intervention in Switzerland. In: Proc., $13^{\text {th }}$ Int. Interpraevent Congress 2016, Lucerne, Switzerland, Vol. 1, pp. 10051013.

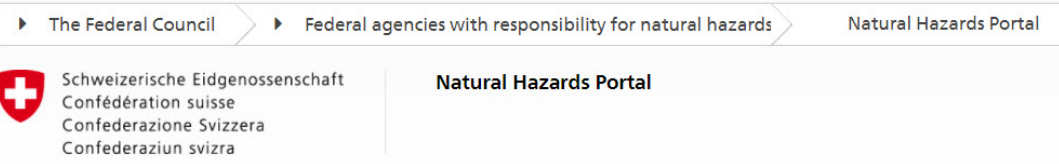

\begin{tabular}{|l|l|l|l|}
\hline $\begin{array}{l}\text { Current Natural } \\
\text { Hazards }\end{array}$ & $\begin{array}{l}\text { Dealing with natural } \\
\text { hazards }\end{array}$ & Previous events & About us \\
\hline
\end{tabular}

Current natural hazards

Maps

Fire ban in force

\section{Current natural hazards situation in Switzerland}

location / ZIP O.

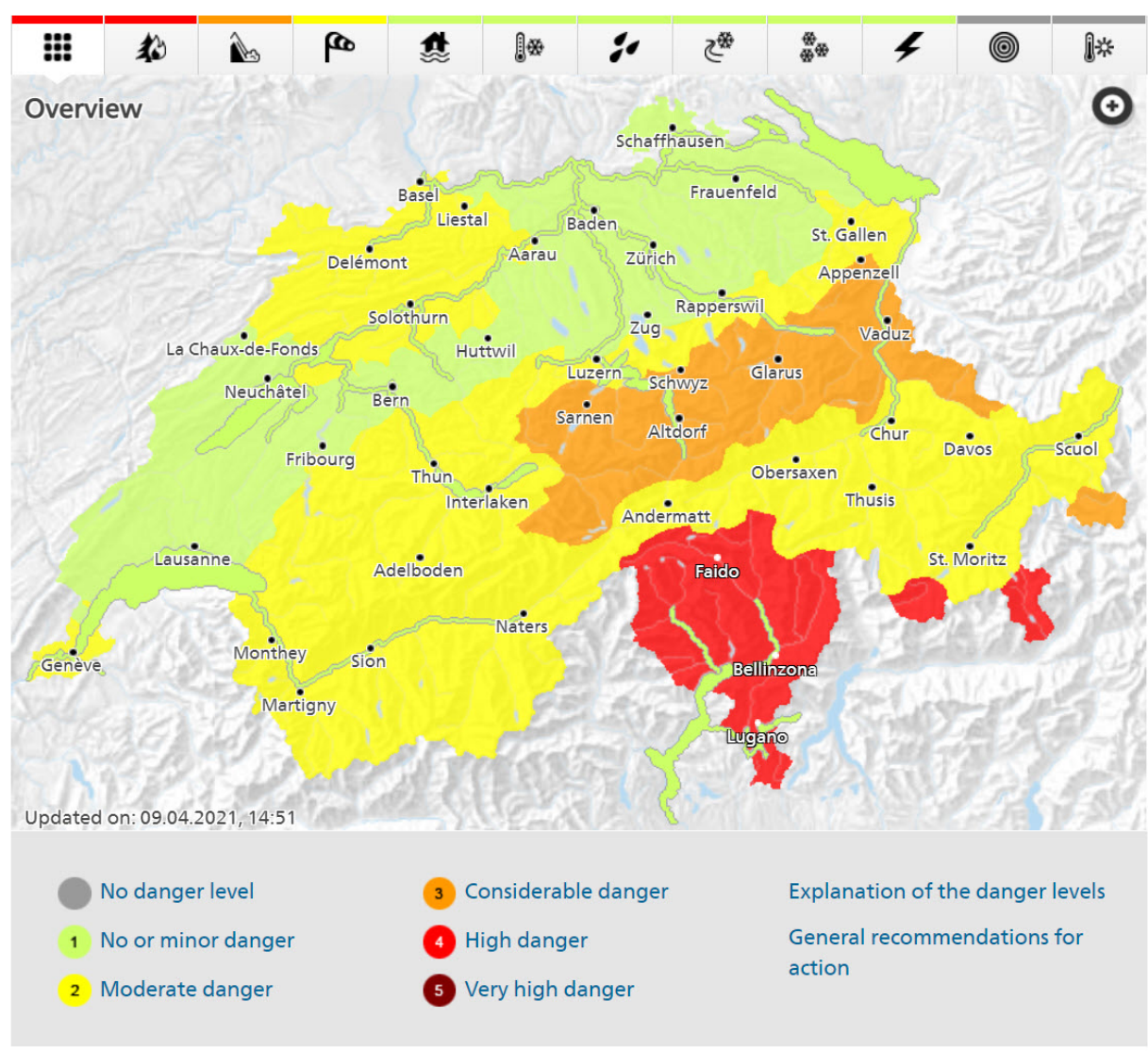

Current warnings issued for Switzerland (18 Messages) • hide

Effective from: 09.04.2021

Measures such as fire bans are imposed by the cantons. These measures may vary from canton to canton.

- Affected regions

Figure 1: Synoptic overview hazard map of the Swiss natural hazard portal. 